\title{
Effect of Low Frequency Magnetic Field on Germination of Onion (Allium cepa L.) Seeds
}

\author{
L. Kubisz ${ }^{a, b}$, R. HoŁubowicz ${ }^{c}$, M. Gauza ${ }^{a}, \mathrm{H}_{\text {. Li }}{ }^{d}$, D. Hojan-Jezierska ${ }^{a, b}$ \\ AND F. JAROSZYK ${ }^{a, b}$ \\ ${ }^{a}$ Department of Biophysics, Poznań University of Medical Sciences, A. Fredry 10, 61-701 Poznań, Poland \\ ${ }^{b}$ Higher Vocational State School, Piła, Poland \\ ${ }^{c}$ Department of Seed Science and Technology, Poznań University of Life Sciences, Poznań, Poland \\ ${ }^{d}$ Cotton Research Center, Jinan, Shandong Province, P.R. China \\ Commercial seed lots of onion (Allium cepa L.) of the cultivars "Octavia" and "Eureka" were soaked for $12 \mathrm{~h}$ \\ in water of the temperature $20^{\circ} \mathrm{C}$, then they were exposed to low frequency magnetic field $(20 \mathrm{mT})$ for 10,30 , \\ and $60 \mathrm{~min}$. The field was generated using a standard device for magnetic stimulation VIOFOR JPS applied \\ in human medical treatment. Next, the seeds were evaluated for energy and capacity of germination, length of \\ the received germs as well as fresh masses of the obtained seedlings using the routine methods recommended by \\ the International Seed Testing Association. For the seeds of the cultivar "Octavia", the field did not affect the \\ energy of germination, however it did improve in all tested treatments their germination capacity. In the best of \\ them $(60 \mathrm{~min})$, the germination capacity increased by $4.6 \%$. For the seeds of the cultivar "Eureka", the tested \\ field increased their energy of germination, which improves evenness of plants emergences in the field and has \\ a significant importance for horticultural practice. When the seeds were exposed to the field for 60 min, their \\ germination energy increased from $40 \%$ (control) to $63 \%$. This result was accompanied by no differences in both \\ length of germs and fresh masses of the received from them seedlings.
}

PACS: 87.17.-d, 87.18.Nq

\section{Introduction}

Effect of magnetic fields on growth and development of plants has been an object of numerous research carried out for over 80 years [1-4]. Weak (about $50 \mu \mathrm{T}$ ) magnetic field was one of the natural factors influencing evolution of all living organisms on the Earth [5]. Due to the lack of specific magnetic receptors, when testing effect of low frequency magnetic fields (LFMF) on the living organisms, including plants, the received results can be related either to changes in concentration of certain characteristic compounds treated like biological indicators, e.g. plant hormones, or to changes in the behaviour of single individuals or population. From the practical point of view, especially interesting is a possibility to use LFMF to stimulate germination of seeds of cultivated plants.

In case of seeds, it can be energy or capacity to germinate, length of upper or lower part of the seedling or its fresh or dry mass. On this issue, many experiments had been done on the plant species important in agriculture, horticulture and forestry, amongst others such as wheat [4], barley [6], rice [7], maize [8], soybean [9, 10], sunflower [11], bean [12], tomato [13], cucumber [14], onion [15] and spruce [16]. The effect of the magnetic field on the seed germination is not univocal and the received results, what happens, are even contradictory. In most of them, however, the effectiveness of the magnetic field stimulation is evaluated based on the same two parameters. These are: speed of germination (also called energy of germination), measured in the laboratory in so-called "first counting", which depends upon the species, i.e. after 4, 6 or 7 days and the final number of normally germinated seeds (also called capacity of germination), measured in the laboratory after longer time in so-called "last counting", which depends upon the species, i.e. after $7,12,14,21$ or 28 days. These procedures, regulated by the rules of the International Seed Testing Association (ISTA), have been routinely used in the seed testing stations [17], and thereby - reliable and checked for practice. A result of higher energy of germination is often, stronger development of a radicle, increased fresh mass of the whole seedling and thereafter a plant. This, usually, results in better plant useful characters, e.g. yield of roots, bulbs or leaves [18].

According to the available FAO data [19], onion is now the third (after tomato and cabbages) most important vegetable produced in the world. For many years, it has also been the most important fresh vegetable exported from Poland. Its seeds are expensive, amongst others, 
due to, as no other vegetable species, fast losing their germination capacity [20]. It exposes seed companies all over the world to huge losses [21]. Therefore, since many years there has been a search for simple and cheap methods to improve seed germination of onion and other agricultural and horticultural crops [22].

The main purpose of the carried out research was to check if LFMF can affect germination of onion commercial seeds.

\section{Materials and methods}

The research was carried out on the commercial seeds of onion (Allium cepa L.) of the cultivars "Octavia" and "Eureka" received from 2 Polish seed companies "Torseed" SA, and "CNOS" Poznań. Both cultivars are commonly used in professional production in large horticultural farms in Poland. Theie seed quality met the actual market standards.

Before starting the experiment, the seeds were surface disinfected by soaking them in the $2 \%$ hydrogen peroxide then dried out by putting them on the blotting paper. Prepared that way seeds were soaked in the room temperature $\left(20^{\circ} \mathrm{C}\right)$ in the distilled water for $12 \mathrm{~h}$. After that time, they were soaked out, surface dried and placed on the blotting paper in the Petri dishes. The seeds were then exposed to LFMF $20 \mathrm{mT}$ magnetic field for 10, 30, and $60 \mathrm{~min}$.

The magnetic stimulation was done using the device VIOFOR JPS used for medical treatment. The applied signal has followed the routine instruction provided by the device's producer [23]. The Petri dishes with the seeds were located in the middle of the geometrical applicator of the diameter $60 \mathrm{~cm}$. They were not in the thermal contact with the coil generating magnetic field. This allowed to eliminate the increase of the sample temperature during their exposure. Induction of the geomagnetic field and the field used for magnetic stimulation was controlled by using a magnetometer type C-42 Chauvin-Amoux. The control seeds were not exposed to the LFMF.

The tests were run in 3 replications of 100 seeds placed in 6 Petri dishes on the 6 layers of blotting paper. Each dish had 50 seeds. After finishing the exposition, the dishes were closed and placed in the darkness in the thermostat at the temperature $20^{\circ} \mathrm{C}\left( \pm 1^{\circ} \mathrm{C}\right)$. The conditions of the seeds germination followed all routine seed testing rules given by ISTA. During the tests, first and last countings were done, after 6 and 12 days, respectively. During the tests, the amount of water in the Petri dishes was completed, always to full capacity of the blotting papers. When evaluating the germination of seeds in both countings, the following groups were measured:

(1) germinated seeds, which gave normal seedlings, (2) abnormal seedlings, (3) dead seeds, (4) ungerminated, fresh seeds [17].

In other experiment, the seeds after being exposed to the LFMF were placed in one line on a set of a double blotting paper. Then they were rolled up, tied on both ends with a rubber and placed vertically into a flask with the distilled water. Then they were treated the same way as described previously. After 6 days, the sets with the seeds were unrolled and the lengths of the individual lower seedling parts (radicles) were measured.

In other experiment, the received after 6 days seedlings from treated and control seeds from each 2 Petri dishes (100 seedlings) were weighted and a mean fresh mass of individual seedlings for each replication and treatment was calculated.

The received results were analyzed in terms of variance and the significance of the received mean values was evaluated based on the Duncan and Tukey tests for $\alpha=0.05$.

\section{Results}

The effect of investigated LFMF on germination energy of onion seed of the cultivar "Octavia" was various. This was observed independently of the used treatments. The energy of germination of the seeds hesitated from $53 \%$ to $81 \%$. Still they did not significantly differ from these values for the check seeds (Table I). However, the used magnetic fields did improve their germination capacity (Table II). It was observed in all tested treatments with the use of the LFMF. In the best of them, in which the seeds were exposed to the field for $60 \mathrm{~min}$, their germination capacity increased by $4.6 \%$ in comparison to the control seeds $(78.9 \%)$. The detailed examination of the received seedlings showed that this was a result of lowering a percentage of abnormal (deformed) seedlings in the tested samples (Table III). This was observed in all tested seeds exposed to the LFMF.

TABLE I

Effect of LFMF on the energy of germination (\%) of the onion seeds of the cultivar "Octavia".

\begin{tabular}{c|c|c|c|c}
\hline \hline \multirow{2}{*}{ Replications } & \multicolumn{4}{|c}{ Exposure time } \\
\cline { 2 - 5 } & Control & $10 \mathrm{~min}$ & $30 \mathrm{~min}$ & $60 \mathrm{~min}$ \\
\hline 1 & 72.0 & 77.0 & 81.0 & 68.0 \\
2 & 64.0 & 71.0 & 74.0 & 77.0 \\
3 & 63.0 & 68.0 & 71.0 & 73.0 \\
4 & 63.0 & 66.0 & 67.0 & 69.0 \\
5 & 60.0 & 64.0 & 66.0 & 69.0 \\
6 & 53.0 & 63.0 & 53.0 & 55.0 \\
\hline Mean value & $62.6 \mathrm{a}^{*}$ & $68.3 \mathrm{a}$ & $69.0 \mathrm{a}$ & $68.7 \mathrm{a}$ \\
\hline
\end{tabular}

* Means followed by the same letters are not significantly different according to the Duncan test for $\alpha=0.05$.

The effect of the tested magnetic field on the seed of the cultivar "Eureka" was more stable than of the cultivar "Octavia" (Fig. 1). In the best combination, the seeds exposed to the seeds to this field for $60 \mathrm{~min}$, increased their energy of germination from $40 \%$ (control seeds) to $62 \%$. In the rest treatments, the differences were smaller: for 30 and 10 min exposures, the received germination energies were $53 \%$ and $46 \%$, respectively. 
TABLE II

Effect of LFMF on the capacity of germination (\%) of the onion seeds of the cultivar "Octavia".

\begin{tabular}{c|c|c|c|c}
\hline \hline \multirow{2}{*}{ Replications } & \multicolumn{4}{|c}{ Exposure time } \\
\cline { 2 - 5 } & Control & $10 \mathrm{~min}$ & $30 \mathrm{~min}$ & $60 \mathrm{~min}$ \\
\hline 1 & 77.0 & 80.0 & 84.0 & 80.0 \\
2 & 77.0 & 82.0 & 83.0 & 84.0 \\
3 & 78.0 & 82.0 & 85.0 & 85.0 \\
4 & 84.0 & 84.0 & 82.0 & 84.0 \\
5 & 81.0 & 82.0 & 82.0 & 84.0 \\
6 & 76.0 & 85.0 & 81.0 & 84.0 \\
\hline Mean value & $78.9 \mathrm{~b}^{*}$ & $82.5 \mathrm{a}$ & $82.9 \mathrm{a}$ & $83.5 \mathrm{a}$ \\
\hline
\end{tabular}

* Means followed by the same letters are not significantly different according to the Duncan test for $\alpha=0.05$.

TABLE III

Effect of the LFMF pretreatment on onion cv. "Octavia" seeds on their percentage of abnormal seedlings in the germination test.

\begin{tabular}{c|c|c|c|c}
\hline \hline \multirow{2}{*}{ Replications } & \multicolumn{4}{|c}{ Exposure time } \\
\cline { 2 - 5 } & Control & $10 \mathrm{~min}$ & $30 \mathrm{~min}$ & $60 \mathrm{~min}$ \\
\hline 1 & 22.0 & 18.0 & 15.0 & 19.0 \\
2 & 23.0 & 18.0 & 17.0 & 15.0 \\
3 & 21.0 & 17.0 & 15.0 & 14.0 \\
4 & 15.0 & 16.0 & 17.0 & 15.0 \\
5 & 17.0 & 17.0 & 16.0 & 15.0 \\
6 & 21.0 & 13.0 & 17.0 & 15.0 \\
\hline Mean value & $19.8 \mathrm{a}^{*}$ & $16.5 \mathrm{~b}$ & $16.2 \mathrm{~b}$ & $15.5 \mathrm{~b}$ \\
\hline
\end{tabular}

* Means followed by the same letters are not significantly different according to the Duncan test for $\alpha=0.05$.

The effect of the tested magnetic fields on the germination capacity of the onion seeds of the cultivar "Eureka" was similar to the previous cultivar, i.e. they caused its increase by about 6\% (Fig. 2). However, this result was not proved to be significantly different from the test seeds. When looking at the germinating seeds, one could

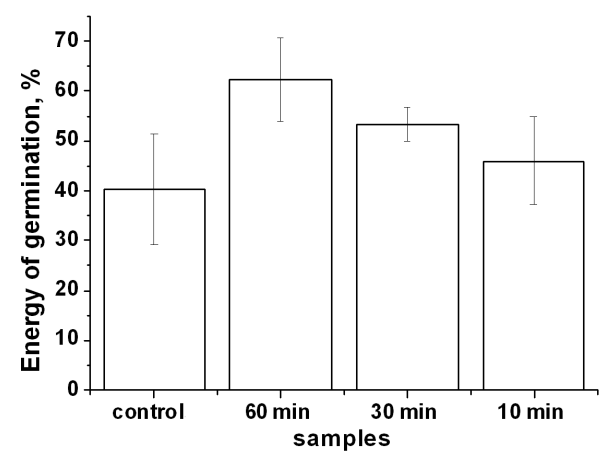

Fig. 1. Effect of LFMF on germination energy of onion seeds of the cultivar "Eureka" (the vertical bars stand for the standard deviation of the mean).

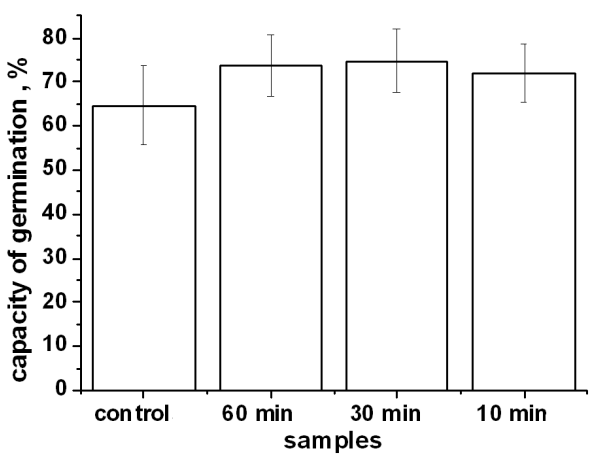

Fig. 2. Effect of LFMF on the capacity of germination (\%) of the onion seeds of the cultivar "Eureka".

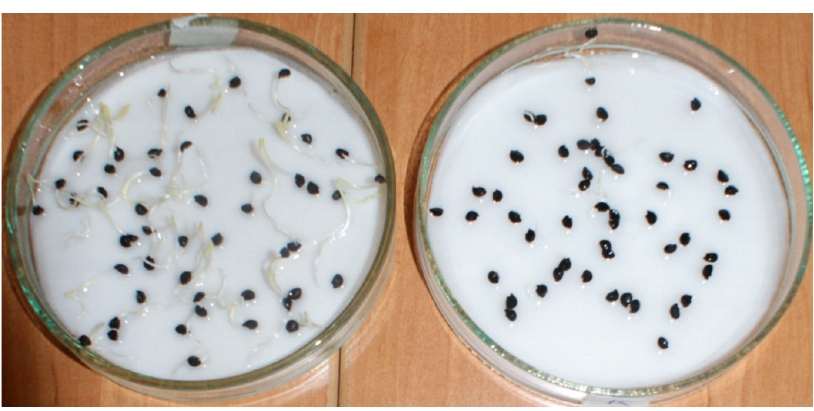

Fig. 3. Onion seeds of the cultivar "Eureka" exposed for 60 min to LFMF (left) and germinated for 6 days at $20{ }^{\circ} \mathrm{C}$ with clearly seen long roots. Right - the control seeds.

clearly see differences in the lengths of radicles, which in the seeds exposed to the LFMF were longer (Fig. 3), however, the received variability was big in the extent, which resulted in that the received differences were statistically not proved. Similar results were received for the fresh mass measurements. The masses of the seedlings received from the seeds exposed to the LFMF were bigger than the ones from the control seedlings. These differences, however, due to high variability of the received data, were not proved to be significantly different.

\section{Discussion}

Since many years one has been observing problems with storing onion seeds [24]. From the point of practical seed technology, it has been known that in standard conditions, i.e. at the air temperature in a seed storing house $5^{\circ} \mathrm{C}$ and its relative humidity $40-60 \%$ with the seeds of seed moisture content $9 \%$, after 7-8 months of storing, their germination significantly declines [21]. For this reason, for many years there have been research works to develop any fast and cheap method, which could allow, on one side - to improve their germination, on the other one - to prolong their use for sowing [25].

Exposing, in the carried out experiment, the seeds of two onion cultivars to the LFMF did increase their germination. It concerned both their energy and capacity of 
germination. The received results are in accordance with the results received by other researchers who carried out their experiments on the seeds of other species of cultivated plants $[4,6,15]$. Exposing in these experiments seeds of maize to the magnetic field of intensity of 125 and $250 \mathrm{mT}$ [8], seeds of sunflower -50 and $200 \mathrm{mT}$ [11], seeds of rice - $200 \mathrm{mT} \mathrm{[26]} \mathrm{and} \mathrm{100-1000} \mathrm{mT}$ [27], seeds of cucumbers $-250 \mathrm{mT}$ [28], seeds of rape $-50-250 \mathrm{mT}$ [29], seeds of broad bean - from 200 to $1000 \mathrm{mT}$ [30], seeds of the mung bean - 2-8 mT [31], seeds of winter wheat - $40 \mathrm{mT}[32]$, seeds of Chinese cabbage from 0.4 to $20 \mathrm{mT}$ [33] as well as seeds of pepper $100 \mathrm{mT}[34]$, caused increase of their both energy and capacity of germination. Moreover, it was often accompanied by elongation of radicles and increase in seedlings' fresh mass.

The received by us results are contradictory to the results of the work done by Tkalec et al. [15] from Croatia. In their experiments, the onion seeds were exposed to radiofrequency electromagnetic field for 2 and $4 \mathrm{~h}$ of 400 to $900 \mathrm{~Hz}$ at field strengths $10,23,41$ and $120 \mathrm{~V} \mathrm{~m}^{-1}$. The used electromagnetic fields did not affect the germination of the seeds. Moreover, when used at the longest and highest range ( 41 and $120 \mathrm{~V} \mathrm{~m}^{-1}$ ), it caused disorders in mitotic activity of meristematic cells in the seedlings' roots. On the other hand, however, as in our experiments, the Croatians did not notice any effect of the tested electromagnetic fields on the roots' length during germination.

Offered today on the market vegetable seeds, including onion ones, have a very good quality. Their germination, measured in the laboratory conditions, i.e. better than met in the field, often exceeds $85 \%$. Efforts of seed companies producing such seeds and then deliver them on the market, consist on developing any method, which could enable improving their germination even by only $3-5 \%$ $[22,35]$. In this context, the received in the experiment results, in which the used LFMF increased the germination energy of onion seeds of the cultivar Eureka by $23 \%$, should be considered as promising in terms of using the same method to improve germination of seeds of other plant species.

The received by us results proving the effect of LFMF on the seeds' germination could be explained, as for plants, by increased production of plant hormones. If so, it would be then analogical to human and animals' response to this kind of stimulation, although results of such experiments are not available at the moment $[36,37]$. The reason of the observed by us magnetic response could be also a change in the ions concentration on both sides of cell membrane caused by appearance of the Lorentz force (the Hall effect) or the result of the so-called ion cyclotron resonance [38]. It needs to be said here that for some treatments of static and LFMF, their interaction with the cell membrane protein creating $\mathrm{Ca}^{++}$ions' channels. In the carried out experiment, such conditions: induction of the low frequency magnetic field of 13 to $114 \mu \mathrm{T}$ and frequency $80 \mathrm{~Hz}$, were met [39]. Thus this could cause increase of the speed of proliferation of some cells exposed to LFMF [40].

The received results confirmed the possibility to use LFMF to stimulate onion seed germination and indirectly also plant growth. However, further research is needed to check the effect of the tested magnetic fields on seed vigour (measured amongst other in germination test run at lower temperatures) and connected with it other physical characters, e.g. seed drying dynamics. The latter was observed for common bean seeds with different vigour [41]. Another issue worth checking is also an effect of the tested magnetic field on plant emergences and their uniformity in the field as well as their other useful characters.

\section{Conclusions}

The low frequency magnetic field (20 mT) can be successfully used to improve germination of seeds of onion of the cultivars "Octavia" and "Eureka".

The improved germination of the seeds hesitated from 4.6 to $22 \%$. The improvement of the seeds germination was not accompanied by differences in both, length of germs and fresh masses of the received from them seedlings.

\section{References}

[1] P.V. Savostin, Planta 12, 327 (1930).

[2] J.D. Murphy, Am. J. Bot. 29, 1955 (1942).

[3] L.J. Audus, Nature 185, 132 (1960).

[4] S. Pietruszewski, Seed Sci. Technol. 21, 621 (1993).

[5] N.A. Belyavskaya, Adv. Space Res. 34, 1566 (2004).

[6] E. Martínez, J.M. Amaya, Electro-Magnetobiol. 19, 271 (2000).

[7] M.V. Carbonell, J.M. Amaya, Electro-Magnetobiol. 19, $121(2000)$.

[8] M. Florez, M.V. Carbonell, E. Martinez, Environm. Exp. Botany 59, 68 (2007).

[9] L. Sakhnini, J. Magn. Magn. Mater. 310, 1032 (2007).

[10] W.C. Mo, Z.J. Zang, Y. Liu, G.J. Zhai, Y.D. Jiang, Q.R. He, Adv. Space Res., (2011).

[11] A. Vashisth, S. Nagarajan, J. Plant Physiol. 167, 149 (2010).

[12] S. Lama, J. Magn. Magn. Mater. 310, 1032 (2007).

[13] Jae-Duk, H. Moon, S. Chung, J. Electrostat. 48, 103 (2000).

[14] Y. Yao, Y.A. Li, Y.Q. Yang, C.Y. Li, Environm. Exp. Botany 54, 286 (2005).

[15] M. Tkalec, K. Malaric, M. Pavlica, B. Pevalek-Kozlina, Mutation Res. 672, 76 (2009).

[16] R. Ruzic, A. Jeglic, D. Fefer, Can. J. Forest Res. 28, 609 (1998).

[17] Anonymous, Seed Sci. Technol. 27, Suppl. Rules, 27, 123, 155, 196 (1999). 
[18] L.O. Copeland, M.B. McDonald, Principles of Seed Science and Technology. 2nd ed., Burgass Publ. Co., Minneapolis, Minnesota 1995.

[19] http://faostat.fao.org, access (23.09.2010).

[20] M. Black, J.D. Bewley, P. Halmer, The Encyclopedia of Seeds Science, Technology and Uses, CABI, Oxfordshire 2006.

[21] R.A.T. George, Vegetable Seed Production, Longman, London 1985.

[22] P. Halmer, Acta Hort. 771, 17 (2008).

[23] http://www.medandlife.co, access (17.04.2011).

[24] J. Korohoda, Seed Production of Vegetable Plants, PWRiL, Warszawa 1974 (in Polish).

[25] A.F. Kelly, Encyclopaedia of Seed Production of World Crops, Wiley, Chichester 1998.

[26] J.L. Xia, L.Y. Yi, X.Y. Liu, Songliao J. 1, 11 (2000) (in Chinese).

[27] J. Xu, S.Y. Zheng, Seeds 28, 86 (2000) (in Chinese).

[28] L.P. Zou, H.P. Gao, Z.Q. Gui, J. Hubei Agric. Sci. 3, 51 (2002) (in Chinese).

[29] Z.Q. Liu, Z.P. Hu, Z.Q. Xie, J. Anhui Agric. Sci. 36, 91 (2008) (in Chinese).

[30] H.M. Gong, J. Anhui Agric. Sci. 35, 6723 (2007) (in Chinese).
[31] J. Zhu, X. Liu, J.K. Hong, Z.H. Hu, Acta Bot. Boreal. Occident. Sin. 23, 792 (2003) (in Chinese).

[32] R.D. Shen, X.W. Li, Y.S. Peng, J.H. Wang, Acta Laser Biol. Sin. 8, 42 (1999) (in Chinese).

[33] Q.X. Liu, L.C. Yu, J. Anhui Agric. Sci. 38, 13626 (2010) (in Chinese).

[34] Y.H. Liu, B.X. Huang, R.Z. Zhang, X.B. Yuan, C.J. Liang, M.N.Wang, J. Jinan Univ. 17, 286 (2003) (in Chinese).

[35] G. Jamieson, Acta Hort. 782, 143 (2008).

[36] R.M. Mostafa, Y.M. Mostafa, A. Ennaceur, Physiol. Behav. 76, 589 (2002).

[37] Z. Forgács, G. Tuhórczy, K. Paksy, L.D. Szabó, Bioelectromagnetics 19, 429 (1998).

[38] A.R. Liboff, Biol. Phys. 9, 99 (1985).

[39] C.L.M. Koch, M. Sommarin, B.R.R. Person, L.G. Sabford, I.L. Eberhard, Bioelectromagnetics 24, 395 (2003).

[40] C. Lei, H. Berg, Bioelectrochem. Bioenerg. 45, 261 (1998).

[41] K. Ratajczak, R. Hołubowicz, Folia Hort. 20, 85 (2008). 